\title{
Maltodextrin and Chitosan Polymers as Inhibitors for the Corrosion of Carbon Steel in 1.0 M Hydrochloric Acid
}

\author{
M. Abdallah ${ }^{1,2, *}$, A. Fawzy ${ }^{1,3}$, H. Hawsawi $^{1}$ \\ ${ }^{1}$ Chemistry Department, Faculty of Applied Science, Umm Al-Qura University, Makkah, Saudi \\ Arabia \\ ${ }^{2}$ Chemistry Department, Faculty of Science, Benha University, Benha, Egypt \\ ${ }^{3}$ Chemistry Department, Faculty of Science, Assiut University, Assiut, Egypt \\ *E-mail: metwally555@yahoo.com
}

doi: $10.20964 / 2020.06 .82$

Received: 20 February 2020 / Accepted: 13 April 2020 / Published: 10 May 2020

\begin{abstract}
The inhibition impacts of two water-soluble polymers viz., maltodextrin and chitosan on the dissolution of carbon steel in $1.0 \mathrm{M} \mathrm{HCl}$ solution were investigated by three dissimilar techniques. The investigation results indicated that the inhibition efficiencies of the examined polymers increased with their concentrations and reduced by raising temperature. The results obtained from polarization measurements proved that the investigated polymers act as mixed type inhibitors. The acquired high inhibition efficiencies of the studied polymers may be owing to powerful adsorption of the polymer molecules on the C-steel surface resulting in the construction of protective layers. Adsorption of the tested polymers on the steel surface was set to accord with Freundlich adsorption isotherm. The inhibition efficiency of chitosan was set to be higher than maltodextrin because of its high molecular mass that increases the surface area of steel covered by the polymer. The acquired thermodynamic parameters for adsorption indicated that the adsorption process is spontaneous and endothermic, and the type of adsorption is physical. The acquired outcomes from the dissimilar measurements were in a good agreement.
\end{abstract}

Keyword: Carbon steel; Polymers; Corrosion Inhibitors; Kinetic parameters; Adsorption

\section{FULL TEXT}

(C) 2020 The Authors. Published by ESG (www.electrochemsci.org). This article is an open access article distributed under the terms and conditions of the Creative Commons Attribution license (http://creativecommons.org/licenses/by/4.0/). 